PEREIRA, RB; AGUIAR, FM; TORRES, TB; AMARO, GB; LUCAS, GC; PINHEIRO, JB. 2017. Reação de genótipos de abóbora e morangas a Phytophthora capsici. Horticultura Brasileira 35: 599-603. DOI - http://dx.doi.org/10.1590/S0102-053620170419

\title{
Reação de genótipos de abóbora e morangas a Phytophthora capsici
}

\section{Ricardo B Pereira'; Frederick M Aguiar²; Tiago B Torres³; Geovani Bernardo Amaro; Gilvaine C Lucas ${ }^{4}$; Jadir B Pinheiro ${ }^{1}$}

1Embrapa Hortaliças, Brasília-DF, Brasil; ricardo-borges.pereira@embrapa.br; geovani.amaro@embrapa.br; jadir.pinheiro@embrapa.br; ${ }^{2}$ Universidade de Brasília (UnB), Brasília-DF, Brasil; frederick.aguiar@colaborador.embrapa.br; ${ }^{3}$ Faculdades ICESP, Brasília-DF, Brasil; tiagob.torres@yahoo.com.br; ${ }^{4}$ Universidade Federal de Lavras (UFLA), Lavras-MG, Brasil; gilciavareli@yahoo.com.br

\begin{abstract}
RESUMO
Phytophthora capsici causa prejuízos significativos em cultivos de abóbora (Cucurbita moschata) e morangas (Cucurbita maxima), incluindo a podridão de raízes e coroa, o crestamento foliar e a podridão de frutos, o que pode resultar em até $100 \%$ de perdas na produção. O objetivo deste estudo foi avaliar a reação de genótipos de abóboras e morangas a $P$. capsici. Inicialmente um experimento foi realizado para avaliar a agressividade de isolados de $P$. capsici de diferentes regiões. Posteriormente, dois experimentos foram realizados em casa de vegetação com 16 genótipos de C. moschata e sete de C. maxima em anos distintos, utilizando os isolados PCA 40 e PCA 43 , identificados como os mais agressivos em teste preliminar. Como testemunhas foram utilizadas a cultivar híbrida Jabras e a cultivar de pimentão Cascadura Ikeda (padrões de suscetibilidade ao patógeno). Os genótipos foram semeados em vasos contendo solo autoclavado. Quatorze dias após, as plantas foram inoculadas mediante a deposição

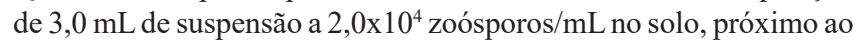
coleto das plantas. A incidência da doença foi avaliada 8 dias após a inoculação. Os experimentos foram conduzidos em delineamento de blocos casualizados, com cinco repetições e parcelas de quatro plantas. Os genótipos apresentaram diferentes níveis de resistência à doença, TX 10350, PHYT-043, CNPH-3001-1 e MAM-2523-1 se destacaram por apresentarem maior resistência à doença em ambos os experimentos. Contudo, nenhum dos genótipos apresentou resistência completa. Os resultados indicam o uso promissor destes genótipos para a obtenção de linhagens resistentes, visando a obtenção de cultivares híbridas resistentes à podridão de fitóftora.
\end{abstract}

Palavras-chave: Cucurbita maxima, Cucurbita moschata, podridão de fitóftora, resistência.

\section{ABSTRACT \\ Reaction of squash and butternut squash genotypes to Phytophthora capsici}

Phytophthora capsici causes significant losses in squash (Cucurbita moschata) and butternut squash (Cucurbita maxima), including root and crown rot, leaf blight and fruit rot, which can result in up to $100 \%$ loss in production. The objective of this study was to evaluate the reaction of squash and butternut squash genotypes to $P$. capsici. Initially an experiment was conducted to evaluate the aggressiveness of isolates of $P$. capsici from different regions. Later two experiments were carried out in a greenhouse with 16 genotypes of C. moschata and seven of C. maxima in different years, using the most aggressive isolates, PCA 40 and PCA 43 identified as the most aggressive in a preliminary test. As control we used the hybrid cultivar Jabras and the pepper cultivar Cascadura Ikeda (susceptibility patterns to the pathogen). The genotypes were sown in pots of four liters containing autoclaved soil. Fourteen days later, plants were inoculated by depositing $3.0 \mathrm{~mL}$ of the suspension of $2.0 \times 10^{4}$ zoospores $/ \mathrm{mL}$ in the soil, near to plant stem. The disease incidence was evaluated 8 days after inoculation. The experiments were conducted in a randomized block design with five replicates of four plants. The genotypes showed different levels of disease resistance, TX 10350, PHYT-043, CNPH-3001-1 and MAM2523-1 stood out because they showed greater degree of resistance to $P$. capsici in both trials. However, none of the genotypes showed complete resistance. The results indicate the promising use of these genotypes to obtain resistant lines, aiming to obtain hybrid cultivars resistant to Phytophthora root rot.

Keywords: Cucurbita maxima, Cucurbita moschata, Phytophthora root rot, resistance.

\section{(Recebido para publicação em 31 de maio de 2016; aceito em 3 de abril de 2017)} (Received on May 31, 2016; accepted on April 3, 2017)

\begin{abstract}
$\mathrm{A}$ $\mathrm{s}$ abóboras, genericamente designadas plantas do gênero Cucurbita (Cucurbita moschata e C. maxima), são amplamente cultivadas no Brasil, com destaque para os estados de São Paulo, Bahia, Minas Gerais, Maranhão, Pernambuco e Rio Grande do Sul. Dependendo da região do país, podem
\end{abstract}

receber nomes diferentes. Produzem frutos de formatos e tamanhos variados, de elevado valor alimentício, e apresentam ampla versatilidade culinária (Filgueira, 2008). Segundo dados da Associação Brasileira do Comércio de Sementes e Mudas, a produção de abobrinhas de modo geral atingiu, em 2012, o volume aproximado de 551 mil toneladas, enquanto a do tipo japonesa superou 726 mil toneladas (Abcsem, 2013).

Durante o cultivo, as abóboras estão sujeitas à ocorrência de inúmeras doenças, as quais causam danos à cultura e, consequentemente, reduzem significativamente a produtividade. Dentre 
essas, a podridão de fitóftora causada pelo oomiceto Phytophthora capsici é considerada uma das mais temidas pelos agricultores, face aos prejuízos causados (Pereira \& Pinheiro, 2014). Em mudas, o patógeno ataca a região do coleto das plantas causando a morte destas em poucos dias. Em plantas adultas, o patógeno ataca as hastes, causando a seca rápida da região acima das lesões, e nos frutos, causa uma podridão característica na face em contato direto com o solo, que se expande rapidamente e exibe um mofo branco acinzentado (Gevens et al., 2012; Pereira \& Pinheiro, 2014). Epidemias da doença são mais comuns em períodos chuvosos e de temperaturas amenas, em áreas irrigadas e em terrenos de baixadas, planos e mal drenados. Dependendo da forma de irrigação ou da constante presença de chuvas, o patógeno se dispersa para as plantas vizinhas, podendo atingir até $100 \%$ da lavoura (Pereira \& Pinheiro, 2014).

O plantio de cultivares suscetíveis à podridão de fitóftora exige a combinação de métodos preventivos para o controle da doença. Contudo, estes nem sempre oferecem a proteção necessária ou não são adotados pelos agricultores. O controle químico não é recomendado, uma vez que não apresenta eficácia contra o patógeno no solo (Pereira \& Pinheiro, 2014). Desta forma, a utilização de cultivares de abóbora com altos níveis de resistência ou tolerância à doença, associada a medidas culturais, como o uso de sementes sadias, rotação de culturas e irrigação adequada são essenciais para o controle do patógeno. Nesse sentido a Embrapa vem trabalhando no desenvolvimento de cultivares resistentes às principais doenças da abóbora, entre elas a podridão de fitóftora.

No Brasil, pesquisas relacionadas à resistência de espécies comerciais de cucurbitáceas a $P$. capsici são escassas. Henz \& Lima (1998) avaliaram cinco cultivares de moranga (C. maxima) e 17 cultivares de abóbora (C. moschata) a $P$. capsici e verificaram que todos os genótipos apresentaram suscetibilidade ao patógeno. Poltronieri (1986) evidenciou que as cultivares Menina Brasileira e Caravela (C. moschata) são mais tolerantes que a cultivar Exposição $(C$. maxima), ainda hoje utilizada em culti- vos comerciais. Contudo, informações a respeito de fontes de resistência e a diversidade genética em germoplasmas de abóboras e morangas para a resistência a $P$. capsici são limitadas, embora se saiba que a disponibilidade de fontes de resistência, principalmente a C. maxima, é muito restrita.

Diante do exposto, o presente trabalho teve por objetivo avaliar a reação de genótipos de abóbora e morangas à podridão de fitóftora causada por Phytophthora capsici.

\section{MATERIAL E MÉTODOS}

Os experimentos foram realizados no Laboratório de Fitopatologia e em casa de vegetação, a $25 \pm 5^{\circ} \mathrm{C}$, e umidade relativa de 60 a $90 \%$, situada no Campo Experimental da Embrapa Hortaliças, Brasília-DF, no período de janeiro de 2014 a março de 2015.

Experimento I - Teste de agressividade de isolados de $P$. capsici

A fim de selecionar os isolados mais agressivos, cinco isolados de $P$. capsici provenientes da coleção de trabalho da Embrapa Hortaliças, obtidos de diferentes regiões produtoras e partes da planta (fruto e haste) e denominados de PCA 10, PCA 14, PCA 30, PCA 40 e PCA 43, foram cultivados em meio de cultura V8 (100 mL de suco V8, 2,0 g de $\mathrm{CaCO}_{3}, 18,0 \mathrm{~g}$ de ágar e água, q.s.p. $1000 \mathrm{~mL}$ ) e inoculados em frutos maduros de abóbora do tipo japonesa, sabidamente suscetível, para a confirmação e recuperação da patogenicidade. Para a inoculação, os frutos foram lavados em água corrente, desinfestados superficialmente com álcool $70 \%$ e deixados para secar em temperatura ambiente. Discos de micélio contendo o patógeno foram fixados na superfície dos frutos com palito de dente autoclavado, de modo que a parte do disco contendo micélio ficasse em contato direto com o fruto. Em seguida, os frutos foram mantidos em câmara úmida $\left( \pm 25^{\circ} \mathrm{C}\right)$ por 3 dias. Quando observados os sintomas de podridão nos frutos, cada um dos isolados do patógeno foi reisolado e multiplicado em meio de cultura V8.

Para o experimento de agressividade foram utilizadas a cultivar híbrida Jabras e a linhagem feminina da 'Jabras'. Como padrão de suscetibilidade, foi adicionado ao experimento a cultivar de pimentão Cascadura Ikeda. Estas foram semeadas em vasos de 4,0 L contendo substrato autoclavado, composto por $85 \%$ de subsolo do cerrado peneirado, $5 \%$ de casca de arroz seca e $10 \%$ de casca de arroz carbonizada, enriquecido com mais $100 \mathrm{~g}$ de calcário dolomítico, $200 \mathrm{~g}$ de superfosfato simples e $60 \mathrm{~g}$ de sulfato de amônio para cada $100 \mathrm{~L}$ de substrato. As plantas foram mantidas em casa de vegetação e irrigadas conforme a necessidade até o fim do experimento. Para a inoculação, foram preparadas suspensões de inóculo de cada um dos isolados que foram previamente cultivados em placas de Petri contendo meio de cultura $\mathrm{V} 8$, nas condições de $25^{\circ} \mathrm{C}$ e fotoperíodo de 24 horas de luz. Após 7 dias, foram adicionados às placas 15 $\mathrm{mL}$ de água destilada, as quais foram mantidas na temperatura de $4^{\circ} \mathrm{C}$ em geladeira por 2 horas e em temperatura ambiente por 40 minutos para a liberação dos zoósporos (Lopes et al., 1999). A suspensão de zoósporos foi coletada e filtrada em gaze e a concentração da suspensão de cada patógeno foi ajudada em hemacitômetro para $2,0 \times 10^{4}$ zoósporos/mL e utilizada imediatamente.

Aos 14 dias após a semeadura, os dois genótipos selecionados foram inoculados mediante a deposição de 3,0 $\mathrm{mL}$ da suspensão de zoósporos com pipeta automática na região do coleto das plantas, próximo ao solo (Santos, 2009). A incidência da doença foi avaliada visualmente quanto à presença dos sintomas da doença (manchas aquosas, murcha e/ou morte), a cada 2 dias, totalizando um período de 21 dias após a inoculação. Em seguida, foi calculada a área abaixo da curva de progresso da incidência da doença (AACPID) de cada isolado em cada genótipo, segundo Shaner \& Finney (1977), determinando-se, assim, a agressividade de cada isolado de $P$. capsici. $\mathrm{O}$ experimento foi realizado em delineamento de blocos casualizados, em esquema fatorial $2 \times 5$ ( 2 genótipos e 5 isolados), com cinco repetições, sendo cada parcela composta por um vaso com quatro plantas. Os dois 
isolados mais agressivos foram PCA 40 e PCA 43.

Experimentos II e III - Reação dos genótipos a $P$. capsici

Para avaliar a reação de genótipos de abóbora e morangas à podridão de fitóftora, dois experimentos foram realizados utilizando os mesmos genótipos, porém em anos distintos. $\mathrm{O}$ primeiro experimento foi realizado de fevereiro a março de 2014 e o segundo de fevereiro a março de 2015. Foram avaliados 16 genótipos de abóbora (C. moschata), CNPH-3001-1, CNPH-1987-1, CNPH-2124-1, CNPH-1067, CNPH-0543-1, CNPH-2116-1, CNPH-526, PHYT-001, PHYT-042, PHYT-043, MAM-2530-1, MAM-2501-1, MAM-2516-1, MAM-2516-2, MAM-2523-1 e TX-10350; e 7 genótipos de moranga $(C$. maxima), CNPH-1985, MAM-2525-1, MAM-2526-1, MAM-2527-1, MAM-2531-1, linhagem feminina 'Jabras' e a cultivar Exposição. Como padrão de suscetibilidade ao patógeno foram adicionadas aos experimentos a cultivar híbrida Jabras (Cucurbita moschata x C. maxima) e a cultivar de pimentão Cascadura Ikeda. Para as inoculações, as mudas e a suspensão de zoósporos foram obtidas conforme metodologia descrita no primeiro experimento. Contudo, as suspensões de zoósporos dos dois isolados (PCA 40 e PCA 43) foram misturadas em partes iguais, mas mantendo-se a concentração de 2,0x10 $10^{4}$ zoósporos $/ \mathrm{mL}$. Aos 14 dias após a semeadura, as plantas foram inoculadas, conforme metodologia descrita no primeiro experimento, e a incidência da doença avaliada visualmente nas quatro plantas da parcela aos 8 dias após a inoculação quanto a presença dos sintomas da doença. As plantas foram mantidas em casa de vegetação a
$25 \pm 5^{\circ} \mathrm{C}$ e umidade relativa de 60 a $90 \%$ durante todo o período experimental, onde foram irrigadas e adubadas conforme a necessidade.

Os experimentos foram realizados em delineamento de blocos casualizados, com cinco repetições e parcelas compostas de um vaso com quatro plantas.

\section{Análises estatísticas}

Os dados de AACPID, referente ao

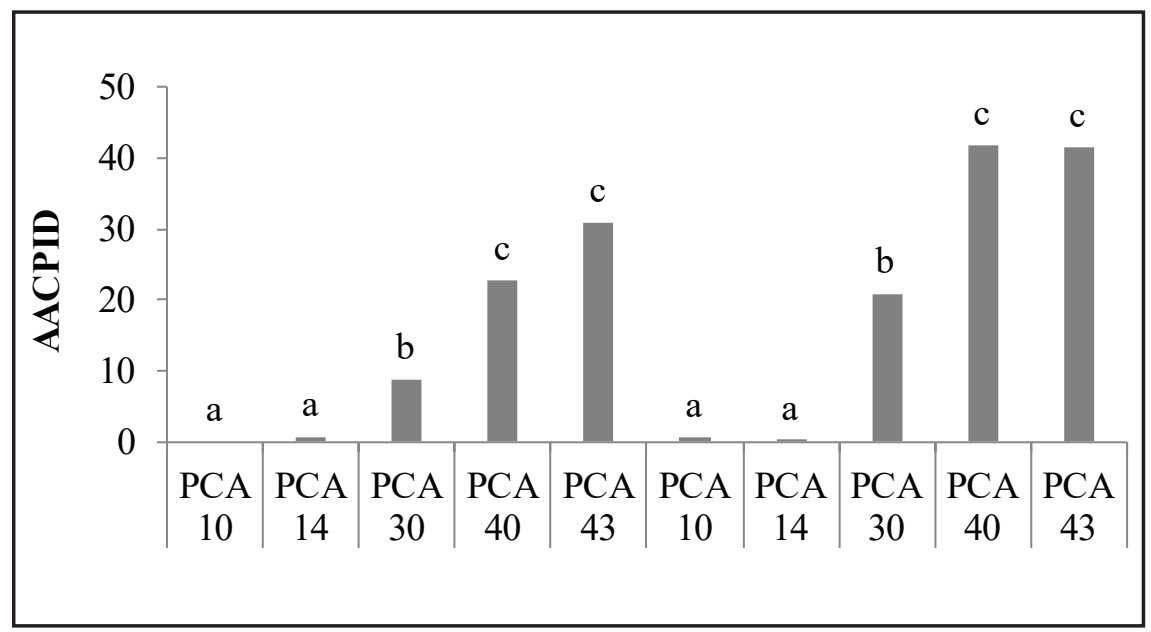

Figura 1. Área abaixo da curva de progresso da incidência da podridão de fitóftora (AACPID) em dois genótipos de abóbora inoculados com cinco diferentes isolados de Phytophthora capsici. Médias seguidas de mesma letra não diferem entre si pelo teste de Scott-Knott $(\mathrm{p} \leq 0,05)$. Dados de número de plantas mortas transformados para $\sqrt{\mathrm{x}+1}$. \{area under the Phytophthota root incidence progress curve (AACPID) in two squash genotypes inoculated by five different Phytophthora capsici isolates. Means followed by the same letter belong to the same group by Scott-Knott test $(\mathrm{p} \leq 0.05)$. Data of number of dead plants transformed to $\sqrt{\mathrm{x}+1}$. Brasília, Embrapa Hortaliças, 2015 .

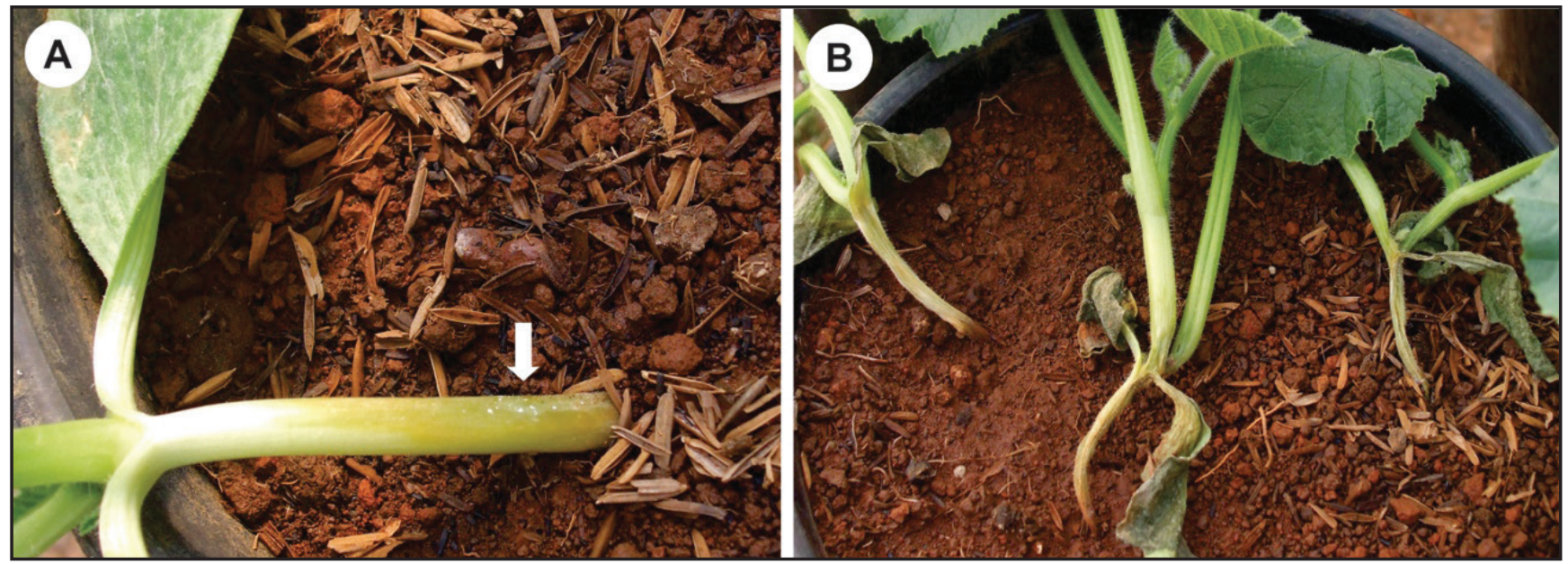

Figura 2. Resposta da cultivar Jabras (Cucurbita moschata $\times$ C. maxima) à inoculação com suspensão de inóculo de isolados de Phytophthora capsici (PCA 40 + PCA 43): lesões aquosas causadas pelo patógeno na região do coleto da planta com a formação de micélio (A) e plantas com sintomas de murcha (B). \{response of Jabras cultivar (Cucurbita moschata $\times$ C. maxima) to inoculation with Phytophthora capsici inoculum suspension (PCA 40 + PCA 43): aqueous lesions caused by plant pathogen in stem region with the formation of mycelium (A) and plants with wilting symptoms (B)\}. Brasília, Embrapa Hortaliças, 2015. 
teste de agressividade dos isolados, e os dados de incidência, referente ao teste de reação dos genótipos ao patógeno, foram submetidos à análise de variância utilizando o software estatístico Sisvar (v.4.5) (Ferreira, 2011). Nos casos de significativa variância, as médias foram agrupadas pelo teste de Scott-Knott $(\mathrm{p} \leq 0,05)$.

\section{RESULTADOS E DISCUSSÃO}

No ensaio de avaliação de virulência dos isolados, verificou-se que as inoculações com os isolados PCA 40 e PCA 43 resultaram em uma maior incidência da doença em ambos os genótipos avaliados (Figuras 1 e 2), seguidos do isolado PCA 30. Os isolados PCA 10 e PCA 14 não diferiram entre si e apresentaram AACPID muito inferiores aos demais. Segundo Marque (2002), a maior agressividade de alguns isolados do patógeno provavelmente está relacionada com seu arsenal enzimático, ou seja, estes possuem um maior número de genes de virulência que codificam, por exemplo, toxinas ou enzimas degradadoras de parede celular (Beltrame, 2010). Contudo, pesquisas adicionais são necessárias para precisar qual é o mecanismo de infecção e o que determina a agressividade dos isolados, além disso este aspecto não faz parte do escopo do presente trabalho.

Em relação aos experimentos de reação dos genótipos de abóbora e morangas a $P$. capsici, verificou-se que os genótipos apresentaram diferentes níveis de resistência/suscetibilidade ao patógeno nos dois experimentos. Contudo, de modo geral, verificou-se maior incidência da doença nas plantas no segundo experimento.

A cultivar Jabras, utilizada como testemunha, apresentou sintomas da podridão de fitóftora quando submetida às condições do estudo, com incidências superiores a $39,5 \%$ em ambos os experimentos (Figura 3). Os genótipos de abóboras TX-10350, PHYT-043, CNPH-3001-1 e MAM-2523-1 apresentaram os melhores resultados no primeiro e segundo experimento, com incidências de 0,0 a $10,0 \%$ e de 12,5 a $18,8 \%$, respectivamente. Os genótipos CNPH-2124-1,
PHYT-042, MAM-25301, CNPH-1067 e MAM-2501-1 não diferiram entre si e apresentaram incidências entre 31,3 e $43,8 \%$ no segundo experimento. Entretanto, não diferiram de TX10350, PHYT-043, CNPH-3001-1, M A M - $2523-1, \quad$ C N P H - 526 , MAM-2516-1, CNPH-0543-1, CNPH-2116-1 e PHYT-001 no primeiro experimento, os quais apresentaram incidências entre 0,0 e 25,0\%.

No primeiro experimento, os genótipos CNPH-1987-1, MAM-2531-1, CNPH-1985 e a testemunha Jabras apresentaram incidências semelhantes, de 40,0 a 50,0\%, seguidos dos genótipos MAM-2516-2, MAM-2527-1 e da linhagem feminina de 'Jabras', com incidências de 60,0 a 75,0\%, das morangas MAM-2525-1, MAM-2526-1 e da cultivar Exposição, com incidências superiores a $85,0 \%$. No segundo experimento, os genótipos de abóbora CNPH-526, PHYT-001, MAM-2516-2, CNPH-0543-1, MAM-2516-1 e CNPH-1987-1 não diferiram entre si e apresentaram incidências de 62,5 a $75,0 \%$, seguidos dos demais genótipos,

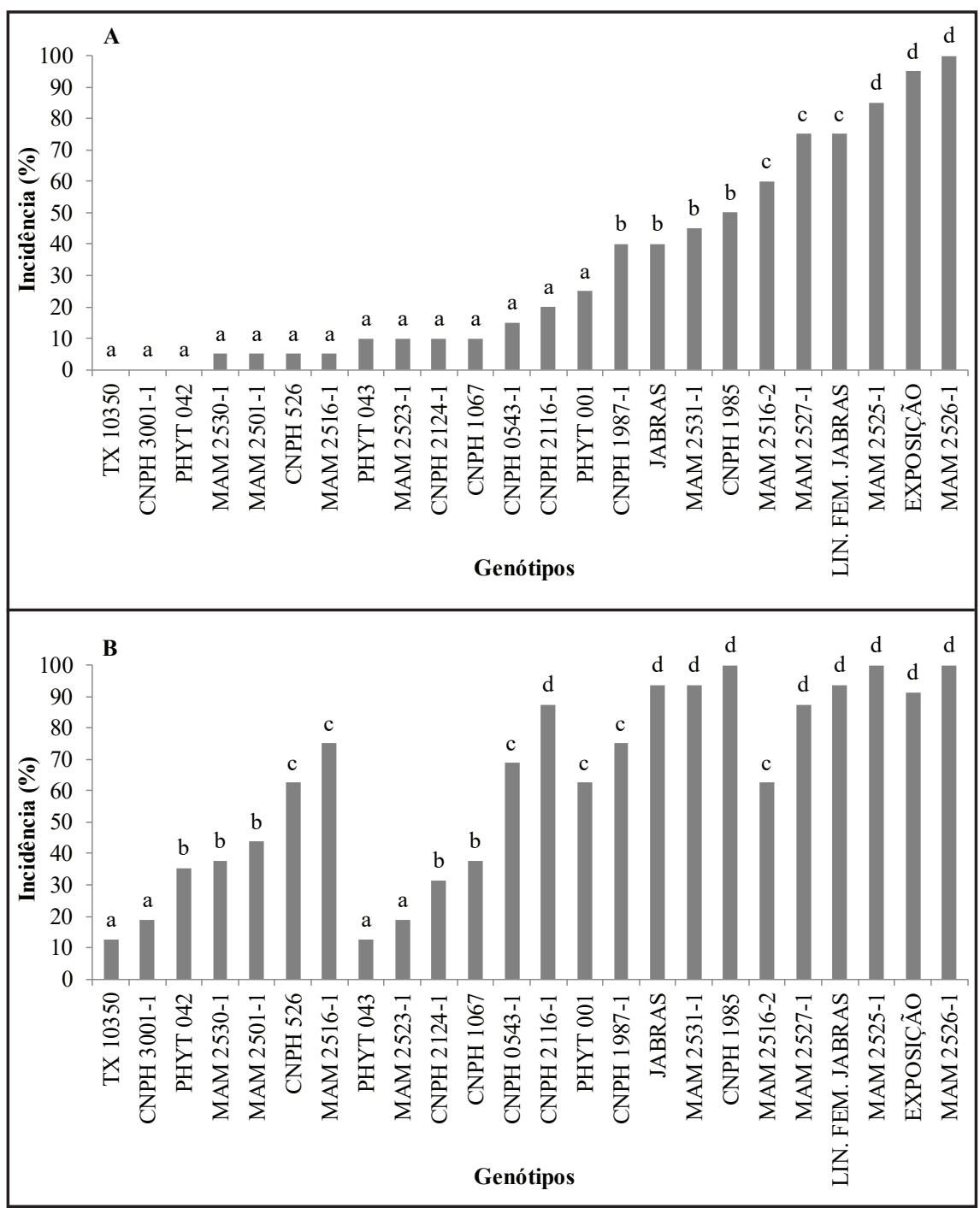

Figura 3. Incidência da podridão de fitóftora em genótipos de abóbora e moranga aos 8 dias após a inoculação com Phytophthora capsici, nos experimentos I (A) e II (B). Médias seguidas de mesma letra não diferem entre si pelo teste de Scott-Knott $(\mathrm{p} \leq 0,05)$. Dados de número de plantas mortas transformados para arcoseno $\sqrt{\mathrm{x}+1}$. \{incidence to Phytophthora rot in squash genotype and butternut squash 8 days after inoculation with Phytophthora capsici, in the experiments I (A) and II (B). Means followed by the same letter belong to the same group by Scott-Knott test $(\mathrm{p} \leq 0.05)$. Number of dead plants transformed data to arcsin $\sqrt{\mathrm{x}+1}$ \}. Brasília, Embrapa Hortaliças, 2015. 
que apresentaram incidências superiores a $87,5 \%$.

Como observado, nenhum dos genótipos de abóbora ou morangas apresentou resistência completa a $P$. capsici e, estes de modo geral, apresentaram resultados semelhantes no primeiro e segundo experimento, com destaque para as abóboras TX-10350, PHYT-043, CNPH-3001-1 e MAM-2523-1. Dentre os genótipos avaliados, verificou-se que as morangas MAM-2527-1, MAM - 2531 - 1, MAM-2525-1, MAM-2526-1, CNPH-1985, linhagem feminina de 'Jabras' e a cultivar Exposição apresentaram maior suscetibilidade a $P$. capsici quando comparadas às abóboras, comportamento também observado por Henz \& Lima (1998).

Até o presente, existem poucos relatos de fontes de resistência a $P$. capsici em cucurbitáceas. A ausência completa de fontes com elevada resistência tem sido reportada por diversos pesquisadores em todo o mundo. Hausbeck \& Lamour (2004) avaliaram 300 acessos de cucurbitáceas e nenhum dos acessos apresentou resistência completa a $P$. capsici. Contudo, a área da lesão em frutos de alguns acessos foi limitada e/ ou a esporulação do patógeno foi significativamente reduzida. Chávez et al. (2011) desafiaram plântulas de 119 acessos de C. moschata, de 39 localizações geográficas, com três isolados de $P$. capsici altamente virulentos e verificaram diferentes níveis de resistência entre os acessos. Contudo, nenhum apresentou resistência completa à doença. Padley et al. (2008) avaliaram a resistência de 115 acessos de $C$. pepo oriundos de 24 países e verificaram diferentes níveis de suscetibilidade à doença, porém nenhum dos acessos apresentou resistência completa ao patógeno. A heterogeneidade para a resistência da podridão de fitóftora em acesso de Cucurbita, previamente relatada por Padley et al. (2009), também foi comprovada no presente estudo. Tal fato provavelmente se deve a forma de manutenção dos acessos, que na maioria das vezes se dá por polinização aberta, por conseguinte haverá traços de heterogeneidade entre os indivíduos para um dado caráter.

Verificamos que o número de acessos de cucurbitáceas com alta resistência ao oomiceto é baixo. Entretanto, a identificação de algumas fontes com elevados níveis de resistência em plântulas de abóboras e morangas é uma importante descoberta para os programas de melhoramento que visam a obtenção de cultivares resistentes. Mesmo na ausência de genótipos de Cucurbita com resistência completa, alguns genótipos têm se mostrado promissores, como as abóboras TX-10350, PHYT-043, CNPH-3001-1 e MAM-2523-1. Neste sentido, segundo Padley et al. (2008), contínuos processos de seleção de indivíduos podem levar à criação de linhagens homogêneas para determinada característica, como resistência a $P$. capsici. Tal método foi utilizado por Davis et al. (2006) para desenvolver uma linhagem de melancia (Citrullus lanatus var. lanatus) resistente à raça 1 de oídio (Podosphaera xanthii) do melão. Contudo, deve-se considerar que diferentes mecanismos genéticos podem ser responsáveis por conferir resistência à doença nos diferentes tecidos da planta (Padley et al., 2008).

Os resultados obtidos no presente estudo subsidiarão os programas de melhoramento genético na seleção e obtenção de linhagens homozigotas de abóboras e morangas resistentes a $P$. capsici, o que permitirá estudos de herança da resistência entre genótipos contrastantes e o desenvolvimento de cultivares resistentes à doença.

\section{REFERÊNCIAS}

ABCSEM - Associação Brasileira do Comércio de Sementes e Mudas. 2015. Levantamento de dados socioeconômicos do agronegócio de hortaliças 2013 ano base 2012. Disponível em http://www.abcsem.com.br/imagens noticias/Apresenta $\% \mathrm{C3} \% \mathrm{~A} 7 \% \mathrm{C} 3 \% \mathrm{~A} 30 \% 20$ completa $\% 20$ dos $\% 20$ dados $\% 20$ da $\% 20$ cadeia $\% 20$ produtiva $\% 20$ de $\% 20$ hortali\%C3\%A7as\%20-\%2029MAIO2014. pdf. Acessado em 26 de março de 2015.

BELTRAME, AB. 2010. Interação Phytophthora nicotianae - porta-enxertos de citros (tangerina Sunki e citrumelo Swingle): efeito no sistema radicular, aspectos fisiológicos e bioquímicos. Piracicaba: ESALQ. 137p (Tese doutorado).

CHÁVEZ. DJ; KEBELKA, EA; CHAPARRO, JX. 2011. Screening of Cucurbita moschata Duchesne germplasm for crown rot resistance to Floridian isolates of Phytophthora capsici Leonian. HortScience 46: 536-540.

DAVIS, AR; LEVI, A; WEHNER, T; PITRAT, M. 2006. PI 525088-PRM, a melon race 1 powdery mildew-resistant watermelon line. HortScience 41: 1527-1528.

FERREIRA, DF. 2011. Sisvar: a computer statistical analysis system. Ciência $e$ Agrotecnologia 35: 1039-1042.

FILGUEIRA, FAR. 2008. Novo manual de olericultura. Viçosa: UFV. 418p.

GEVENS, AJ; ROBERTS, PD; MCGOVERN, RJ; KUCHAREK, TA. 2012. Vegetable disease caused by Phytophthora capsici in Florida. Florida: UF - IFAS Extension. 5p.

HAUSBECK, MK; LAMOUR, KH, 2004. Phytophthora capsici on vegetable crops: Research progress and management challenges. Plant Disease 88: 1292-1303.

HENZ, GP; LIMA, MF. 1998. Resistencia de plântulas de cultivares de cucurbitáceas à podridão-das-raízes causada por Phytophthora capsici. Pesquisa Agropecuária Brasileira 33: 853-859.

LOPES, JF; BRUNE, S; HENZ, GP. 1999. Metodologia de avaliação da resistência de germoplasma de abóboras e morangas a Phytophthora capsici. Horticultura Brasileira 17: 30-32.

MARQUE, JM. 2002. Fisiologia, patogenicidade, sensibilidade a fungicidas e caracterização molecular de Phytophthora capsici Leonian obtido de pimentão (Capsicum annum L.). Botucatu: FCA. 67p (Tese doutorado).

PADLEY JUNIOR, LD; KABELKA, EA; ROBERTS, PD. 2009. Inheritance of resistance to crown rot caused by Phytophthora capsici in Cucurbita. Hortscience 44: 211-213.

PADLEY JUNIOR, LD; KABELKA, EA; ROBERTS, PD; FRENCH, R. 2008. Evaluation of Cucurbita pepo accessions for crown rot resistance to isolates of Phytophthora capsici. Hortscience 43: 1996-1999.

PEREIRA, RB; PINHEIRO, JB. 2014. Phytophthora capsici em cucurbitáceas. Embrapa Hortaliças, Brasília. 8p (Comunicado Técnico, 103).

POLTRONIERI, LS. 1986. Produção de esporângio in vitro, patogenicidade em Cucurbita spp. e controle químico de Phytophthora capsici. Piracicaba: ESALQ. 83p (Dissertação mestrado).

SANTOS, TR. 2009. Metodologias de inoculação em plântulas e reação de acessos de mamoeiro a Phytophthora palmivora. Ilhéus: UESC. $58 \mathrm{p}$ (Dissertação mestrado).

SHANER, G; FINNEY, RF. 1977. The effect of nitrogen fertilization on the expression of slow-mildewing resistance in knox wheat. Phytopathology 67: 1051-1056. 